\title{
College Student Leadership Competencies Development: A Model
}

\author{
Mozhgan Amirianzadeh ${ }^{1}$, Parivash Jaafari ${ }^{1}$, Nadergholi Ghourchian ${ }^{1}$, Bahram Jowkar ${ }^{2}$ \\ ${ }^{1}$ Science and Research Branch, Tehran Islamic Azad university, Tehran, Iran \\ ${ }^{2}$ Faculty of Shiraz university, Tehran, Iran \\ mamireanzadeh15@gmail.com
}

\begin{abstract}
The study has designed a model for assessing student leadership competencies development and affecting factors in university. It is based on the findings in Fars province- Iran. 400 college students were randomly selected from 26 institutions. The study used qualitative (Focus group, individual in-depth interview and library) and quantitative (path analysis) methods. Numerous studies have been carried out examining the effect of involvement and environment variables, leadership attitude and leadership behavior on the student leadership competencies development. However, there is little research conducted on the effect of leadership attitude and leadership behavior such as mediatory variable on the student leadership competencies development. The model suggests that systematic thinking, challenging the process, inspiring a shared vision, enabling others to act, modeling the way and encouraging the heart are considered important in student leadership competencies development. The authors propose that student affair practitioners need to rethink some of the key assumptions of their student leadership and practices in order to meet the needs of a changing student body. Also, college and universities need to be cognizant of these differences, as they develop leadership programs, training opportunities, leadership course and co- curricular and extracurricular activities.
\end{abstract}

\section{Introduction}

According to the Council for the Advancement of Standards (CAS) in higher standards and guidelines [14], the development of leadership "empowers students to mature and develop toward greater levels of leadership complexity integration and proficiency over a period of time (p.114)". A recent study highlights the contrasts between College Students in the 1990s and College students today [9], [8]. "leadership is ultimately about change, and ... effective leaders are those who are able to effect positive change on behalf of others and society [7]. "Change ... is the ultimate goal of the creative process of leadership to make a better world and a better society for self and others [7]". The impact of collegiate institutions on student development is evidenced by:
"Attending College can have a profound effect on one's life "[1]. Drum [4] defined student development as "a process in which an individual undergoes a number of changes toward more complex behavior that result from mastering the increasingly demanding challenges of life" [6]. It is evident that students who spend much time on campus and develop and change during their college life. Astin [1] indicated that the time students spend on campus and the characteristics of their involvement in activities have potential impact on the quality of their campus-wide experiences, student development of leadership has been viewed as one of the most important tasks. According to Astin's involvement theory, there were five basic postulates:

1. Involvement refer to the investment of physical and psychological energy in various objects. The objects maybe highly generalized (the student experience) or highly specific.

2. Regardless of its object, involvement occurs along a continuum; that is, different students manifest different degrees of involvement in a given object, and the same student manifests different degrees of involvement in different objects at different times.

3. Involvement has both quantitative and qualitative features. The extent of a student's involvement in academic work, for instance, can be measured quantitatively (how many hours the student spends studying) and qualitatively (whether the student reviews and comprehends reading assignments or simply stares at the text book and daydreams).

4. The amount of student learning and personal development associated with any educational program is directly proportional to the quality and quantity of student involvement in that program.

5. The effectiveness of any educational policy or practice is directly related to the capacity of that policy or practice to increase student involvement.

Astin [1] argues that it is important to develop young men and women during their college years to become future leaders. Leadership is considered to be a part of life long learning and multidimensional constructs involving competency (skills, ability, attitude, knowledge, and behavior), experiences and processes. Student leadership 
competencies development is a prominent theme and objective in higher education.

\section{Literature Review}

Student development is a term that is used extensively in student affairs practice [5]. Professionals talk about "facilitating student development", offices are titled "student Development", and graduate students study "student development theories". In 1967, san ford defined development as "the organization of increasing complexity" (p.47) [5]. Student leadership development is built on the following premises or beliefs:

- The impact of collegiate institutions on student development is evidenced by: "Attending College can have a profound effect on one's life" [1]. The development of leadership characteristics is one of these effects [16].

- Development is seen as development: Student development is almost universally viewed as a good thing" [5]. Student leadership cannot be neglected as a field of growth development. Many research studies support such an argument [4].

- Leadership is required for individuals in higher education: Student leadership development can be viewed as a synonym of meeting "individual goals" in higher education. Among these goals, student leadership is viewed as a crucial component that college students should achieve [14].

- Student involvement can make a difference: students can benefit from involvement in the campus community. Such gains include student's satisfaction with the institution, positive effects on academic experience and degree completion, and leadership skills [1] [16].

- Student development is definable and can be assessed [1] [10] [19].

Rudolph [17] indicated that Harvard College, the first college in America, came into being early in the history of the colony (in 1936) because the society needed learned clergies and leaders. Increasingly, higher education is being turned to as a source for potential change give its significant role in developing leadership capacity among today's youth [1]". The reasons why it is so important to develop students to become future leaders during his or her college are primarily because leadership development that encompasses various activities and experiences will enhance the ability of college students to make a difference" [1] and prepare them for their prospective roles as tomorrow's leaders [17], And, by doing so, benefit the individual, the institution of higher learning, and the society as a whole [6]. Students learn leadership skills through their involvement in in-class and out-of-class activities [12] [16]. Most of the involvement literature is based on Astin's Theory of Involvement [1]. Factors positively affecting leadership development were living away from home, student-to-student interaction, student to -faculty interaction, involvement in campus activities, and involvement in class activities [1][16][17]. Students' involvement can make a difference in a variety of situations. Students can benefit from involvement in the campus community. Such gains include students' satisfaction with the institution, positive effects on academic experience and degree completion, and leadership skills [2] [18]. Kouzes [10] asserts that leadership behaviors affect student leadership development. Astin [1] argued that student - student interaction has a strong positive impact on the development of student leadership. He stated, "larger-thanaverage increases in Leadership scores are also associated with being a member of a social fraternity or sorority, playing intramural sports, spending time in volunteer work, tutoring other students, participating in a group project for class, and making presentations to class [1].

Wielkiewicz [16] also stated that leadership attitude (hierarchical thinking and systematic thinking) affects student leadership development. He found that males and females (including college students, faculty, staff, and graduate students) differed significantly on both hierarchical thinking and systemic thinking. In the model, entry variables (exogenous variables) include involvement variables [1] [2] [18] and environment variables [1]. Mediatory variables include attitude and behavior variables [9] [10] [11] [19].Response variables (endogenous variables) include student leadership competencies (Figure 1). As such, the issue of fostering the leadership development of college students is a crucial and inevitable one for today's institutions of higher learning. Developing student's leadership ability remains one of the most important tasks in higher education. This research examines the following hypothesis:

Leadership behavior and Leadership attitude are significant mediator variables in relationship between environment and involvement as exogenous variables with student leadership competencies as an endogenous variable.

\section{Analysis of Finding}

The study used qualitative and quantitative methods. Mixed sampling done by Morgan Table was used to obtain the desired sample. 400 college students were randomly selected from 26 institution. The data were collected using the College Student Leadership Development Inventory (CSLDI) and Leadership Competencies Questionnaire (LCQ). The qualitative method was done by focus groups, individual in-depth interviews and library using triangular procedure. To test the theoretical hypothesis, structural equation modeling (SEM) was employed. LISREL was used to develop and test all structural models, in which multiple regression was used and the goodness of fit was calculated. The statistical measures used to assess the goodness of fit for the covariance structural models were: 1) Chi-square 
2) Root Mean Square Error of Approximation (RMSEA)

3) Standardized Root-Mean Residual (SRMR)

4) Non-Normed fit Index (NNFI)

5) Incremental Fit Index (IFI)

6) Goodness of Fit Index (GFI)

7) Comparative Fit Index (CFI)

Figure1 shows conceptual model of relationship between exogenous and endogenous. In this conceptual model there are two exogenous variables (environment and involvement variables), two mediatory variables (attitude and leadership behavior) and one exogenous variable (student leadership competencies). This research used Barron and Kenny steps [3] and Mackinnon [12]. Barron and Kenny [3] have discussed four steps in establishing mediation:

Step1: shows that the initial variables are correlated with the outcome.

Step2: shows that the initial variables are correlated with the mediator.

Step3: shows that the mediator affects the outcome variable.

Step4: shows the comparison of the coefficient calculated in step1 for exogenous variable to endogenous variable with these coefficients in step 3.
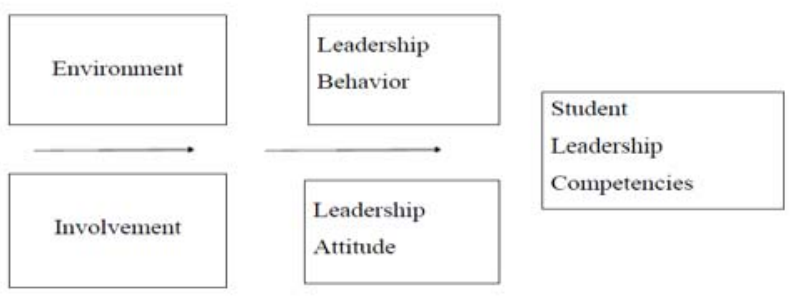

Figure 1. A Conceptual model of student leadership competencies development

Figure 2 shows that environment $(\mathrm{B}=.30, \mathrm{t}=5.30$, $\mathrm{p}<0.0001)$, and involvement variables $(\mathrm{B}=.19, \mathrm{t}=3.41$, $\mathrm{p}<0.001$ ), have positive and significant effect on student leadership competencies.

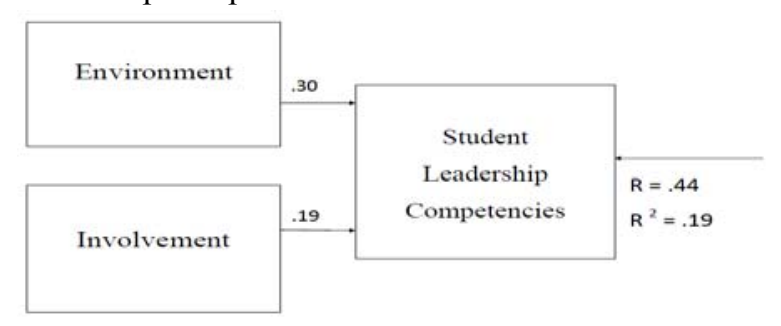

Figure 2.The effect of exogenous variables on endogenous
Figure 3 shows that environment variable has positive and significant effect on behavior variable $(\mathrm{B}=.61, \mathrm{t}=14.69$, $\mathrm{p}<0.0001$ ), and environment variable has a positive and significant effect on attitude variable $(\mathrm{B}=.30, \mathrm{t}=5.23$, $\mathrm{p}<0.0001)$.

Also involvement variable has a positive and significant effect on behavior variable $(B=.22, t=5.30, p<0.0001)$, involvement variable has a positive significant effect on attitude variable $(B=.15, t=2.60, p<.01)$.

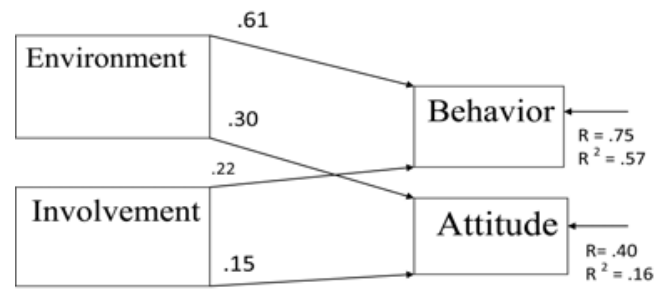

Figure 3. The effect of exogenous variables with mediators' variables.

$$
\text { Mediation }=\frac{\sum a B}{\sum a B+\tau^{\prime}}
$$

Figure 4 shows the effect of mediator variables on student leadership competencies (endogenous variable) by controlling exogenous variable. In this figure both attitude and behavior variables have positive and significant effects on student leadership competencies,

$(\mathrm{B}=.45, \mathrm{t}=10.12, \mathrm{p}=.0001)(\mathrm{B}=.28, \mathrm{t}=4.50$,

$\mathrm{P}=.0001)$, but involvement and environment variables do not have significant effect on this endogenous variable $(\mathrm{B}=-.01, \mathrm{t}=-.15, \mathrm{p}=.87)(\mathrm{B}=-.06, \mathrm{t}=1.20, \mathrm{p}=.22)$.

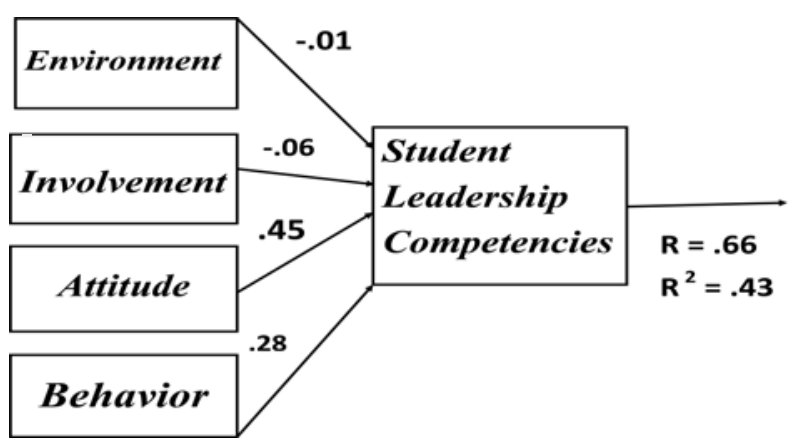

Figure 4. The effect of exogenous variables and mediator variables on endogenous variables

Figure 5 shows final model of student leadership competencies development. 


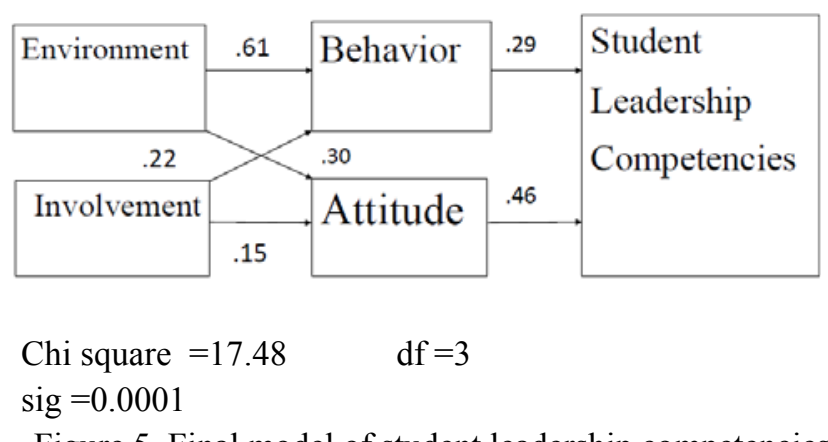

Figure 5. Final model of student leadership competencies

Fit measure of final Model shows the table 1.

Table1. Fit measure of final Model

\begin{tabular}{ccl}
\hline $\begin{array}{c}\text { Statistics for } \\
\text { consistency tests }\end{array}$ & Conditions & $\begin{array}{c}\text { Values and } \\
\text { conclusion }\end{array}$ \\
\hline RMSEA & 0.06 & $0.05-0.08=$ acceptable \\
SRMR & .04 & $.01-.05=$ close fit \\
CFI & 0.95 & $.95-.99=$ close fit \\
IFI & 0.98 & $.95-.99=$ close fit \\
GFI & 0.93 & $.90-.94=$ acceptable fit \\
AGFI & 0.90 & $.90-094=$ acceptable fit \\
NNFI & 0.94 & $.90-.95=$ acceptable fit \\
\hline
\end{tabular}

Indirect effect $=\sum \mathrm{aB}$

direct effect $=\tau^{\prime}$

1) Mediatory role of behavior in relationship between environment and competencies equals (.73) that was significant at $(\mathrm{p}<0.01)$.

2) Mediatory role of behavior in relationship between involvement and competencies equals (.65) that was significant at $(\mathrm{p}<0.01)$.

3) Mediatory role of attitude in relationship between environment and competencies equal (.63) that was significant at $(\mathrm{p}<0.01)$.

4) Mediatory role of attitude in relationship between involvement and competencies equal (.54) that was significant at $(\mathrm{p}<0.01)$.

\section{Contribution to Knowledge}

A lot of research conducted so far (reference) has focused on variables discussed above separately. This research however, has focused on the mediatory role of leadership attitude and leadership behavior in relation with student leadership competencies development. The role of each variable is taken into consideration. It is worthwhile mentoring that there has not been any model like this up to now. The calculated amount shows mediatory role of behavior and attitude between exogenous variables and competency variables. Based on the findings of the present study, the model has proposed that involvement and environment variables are predictors of student leadership development. These results are consistent with the findings of Astin [1], Kuh [12], and Pascarella and Ternzini [16]. The model also has proposed that leadership attitude variables and leadership behavior variables are all predictors of student leadership development .These results are consistent with the findings of Kouzes\& Posner [10] Komives and etal [9]. In the final phase by controlling exogenous variable, attitude and behavior leadership variables are mediatory for student leadership competencies. This model has acceptable goodness-of-fit indices as RMSEA (.06) and p-value (.08) indicated that the model fit the data very well .

\section{Conclusion}

Leadership has gained the attention of researchers world wide. Many people believe that leadership is a way to improve their personal, social, and professional lives [15]. Facilitating student leadership competencies development directly and indirectly helps communities, societies, families and industries. The prior research showed that environment and involvement variables have positive significant effect on student leadership development [1] [12] [16] [18]. Also leadership attitude and leadership behavior have significant positive effects on student leadership development [9] [10] [11]. But this study has showed that the two variables attitude and behavior leadership are mediator variables in student leadership competencies development. Therefore, the mediatory role of leadership attitude and leadership behavior shows the explanatory model. The individual indepth interviews and focus group used in this study have provided a structured time for participants to reflect on their experience, as demonstrated in several comments from student leaders. The indicators of triangulation and conceptual modeling showed the same results. Increasing (promoting) student leadership competencies development demands pays special attention to the following issues: systematic thinking (relationship orientation, ethics, learning orientation change centered, and cooperative leadership process), challenging the process, Inspiring a shared vision, enabling others to act, modeling the way and encouraging the heart. Colleges and universities need to recognize that leadership attitude and leadership behavior as important factors positively affect student leadership competencies development.

These finding have practical implications for students, university faculty, and managers. These findings suggest student leadership competencies development is closely related to attitude leadership variables and behavior leadership variables. Therefore, attitude leadership 
variables and behavior leadership variables are mediatory for student leadership competencies .

\section{Future work}

The future work will involve:

- A longitudinal study of the effects of exogenous variables on the endogenous variables.

- A comprehensive, historical, and contemporary qualitative study should be conducted on the student leadership competencies in higher education.

- A more in-depth comparative qualitative study should be undertaken of the student leadership competencies in higher education.

- A quantitative study based on the following strata: gender, major and class rank.

- Other potential factors, such as pre-college Leadership experiences, parental education achievement, for student leadership development, could possibly be Predictive of student leadership competencies in higher education.

\section{Acknowledgments}

I would like to thank several people who have helped to make this article. A special acknowledgement goes to Dr Jaafari Parivash, Professor Ghourcheian Nadergholi, Dr Jowkar Bahram.

\section{References}

[1] Astin, A., W., What matters in college? Four critical years revisited .San Francisco: Jossey - Bass, 1997.

[2] Abrahamowicz, D., College involvement, perceptions, and satisfaction: A study of membership in student organizations. Journal of college student development. 1988, 29(3), 233- 238.

[3] Baron, R. M., and Kenny, D. A., The moderator- mediator variable distinction in social psychological research: conceptual, strategic and statistical considerations. Journal of personality and social psychology, 1986, 51, 1173, 1182.

[4] Drum, D., Understanding student development. Lnw. H. Morrill, \& J. C. Hurst (Eds), Dimension of intervention for student development, New York: John Willey \& sons. 1980, 1438 .

[5] Evans, J., Nancy and others. Student Development in college Theory Research and practice. Jossey-Bass. 2010.

[6] Green and McDade, Investing in higher education: A handbook of leadership development. Washington D.C: American council on Education, 1991.
[7] Higher Education Research Institute [HERI], A social change model of leadership development (version III).Los Angeles: university of California Los Angeles, Higher Education Research Institute, 1996.

[8] Kiesa, A., Orlowski, A. P., Levine, P., Both, D., Kirby, E. H., Lopez, M.H., and Marcelo, K.B. Millennials talk politics: A study of college student political engagement. College park, MD: Center for information and Research on civic learning and Engagement, 2007.

[9] Komives, R. S., et al., The hand book for student leadership Development. National clearing house for leadership programs. 2011

[10] Kouzes, M., Posner, J., Biech E., A Coach's Guide to Developing Exemplary Leaders:. Making the Most of The Leadership Challenge and the Leadership Practices Inventory (LPI). Jossey -Bass.2010.

[11] Komives et al., Leadership Identity development .A Grounded theory and a leadership Identity Development. International leadership Association .Washington DC, 2004.

[12] Kuh, G. D. and Andreas, R.E., It's about time: Using qualitative methods in student life studies .Journal of college student Development, 1991, 32(5), 397-405.

[13] Mackinnon, D.P. Introduction to statistical mediation analysis. Mahwah, NJ: Erlbaum, 2008.

[14] Miller, T. K., The CAS book of professional standards for higher education. Washington, DC: council for the Advancement of standards in Higher Education, 1997.

[15] Northouse, P., Leadership: Theory and Practice. Sage Publication. 2010.

[16] Pascarella and Ternzini, p.T. How college affects students.san Francisco: Jossey-Bass, 2005.

[17] Rudolph, F., The American college and university: A history Athens: The University of Georgia press, 1990.

[18] Tinto, V. Leaving College: Rethinking the causes and cures of student attrition. Chicago: University of Chicago press, 1993.

[19] Wielkiewicz, R.M., The leadership attitudes and belief scale: An instrument for evaluating college students, thinking about leadership and organizations. Journal of college student development, 2000, 4(3), 335-347. 